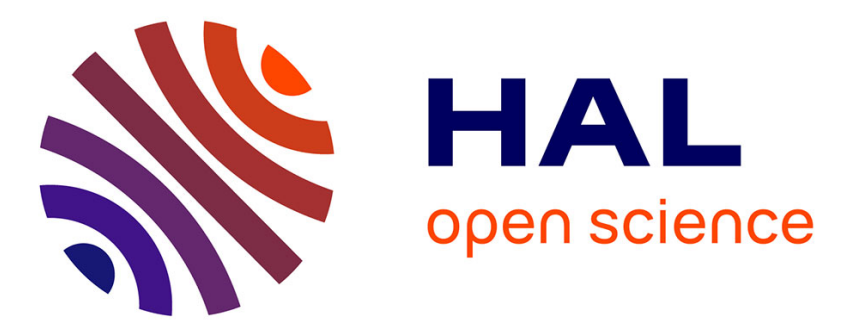

\title{
Cross section measurements for production of positron emitters for PET imaging in carbon therapy
}

S. Salvador, J. Colin, D. Cussol, C. Divay, J.M. Fontbonne, M. Labalme

\section{To cite this version:}

S. Salvador, J. Colin, D. Cussol, C. Divay, J.M. Fontbonne, et al.. Cross section measurements for production of positron emitters for PET imaging in carbon therapy. Phys.Rev.C, 2017, 95 (4), pp.044607. 10.1103/PhysRevC.95.044607 . hal-01555145

\section{HAL Id: hal-01555145 \\ https://hal.science/hal-01555145}

Submitted on 17 Mar 2020

HAL is a multi-disciplinary open access archive for the deposit and dissemination of scientific research documents, whether they are published or not. The documents may come from teaching and research institutions in France or abroad, or from public or private research centers.
L'archive ouverte pluridisciplinaire HAL, est destinée au dépôt et à la diffusion de documents scientifiques de niveau recherche, publiés ou non, émanant des établissements d'enseignement et de recherche français ou étrangers, des laboratoires publics ou privés. 


\title{
Cross section measurements for production of positron emitters for PET imaging in carbon therapy
}

\author{
S. Salvador, J. Colin, D. Cussol, C. Divay, J.-M. Fontbonne, and M. Labalme \\ Laboratoire de Physique Corpusculaire de Caen, ENSICAEN, Université de Normandie, UNICAEN, CNRS/IN2P3, F-Caen, France
}

(Received 23 November 2016; published 11 April 2017)

\begin{abstract}
In light ion beam therapy, positron $\left(\beta^{+}\right)$emitters are produced by the tissue nuclei through nuclear interactions with the beam ions. They can be used for the verification of the delivered dose using positron emission tomography by comparing the spatial distribution of the $\beta^{+}$emitters activity to a computer simulation taking into account the patient morphology and the treatment plan. However, the accuracy of the simulation greatly depends on the method used to generate the nuclear interactions producing these emitters. In the case of Monte Carlo (MC) simulations, the nuclear interaction models still lack the required accuracy due to insufficient experimental cross section data. This is particularly true for carbon therapy where literature data on fragmentation cross sections of a carbon beam with targets of medical interest are very scarce. Therefore, we performed at GANIL in July 2016 measurements on $\beta^{+}$emitter production cross sections with a carbon beam at 25,50 , and $95 \mathrm{MeV} /$ nucleon on thin targets (C, N, O, and PMMA). We extracted the production cross section of ${ }^{10,11} \mathrm{C},{ }^{13} \mathrm{~N}$, and ${ }^{14,15} \mathrm{O}$ that are essential to constrain or develop MC nuclear fragmentation models.
\end{abstract}

DOI: 10.1103/PhysRevC.95.044607

\section{INTRODUCTION}

Light ion beam therapy has been considered for a few decades as an alternative to conventional radio-therapy in the treatment of radio-resistant cancerous tumors. This can be attributed to two main aspects of their physical properties, a maximum deposited energy located at the ion range end (the so-called Bragg peak) and a higher linear energy transfer. Those lead to a more conformal dose deposition to the tumor volume while sparing at best the surrounding healthy tissues and to a better efficiency in killing tumor cells, denoted as the relative biological effectiveness (RBE) [1,2]. However, nuclear interactions of light ions in matter result in a lowered beam intensity at the Bragg peak and the creation of a mixed radiation field composed of projectile and target fragments with different ranges and RBE [4,5]. Nevertheless, fragments production can actually come as an advantage. It is possible to assess the range and position of the beam in the body by comparing computer simulations to positron emission tomography (PET) of the $\beta^{+}$emitters distributions produced by nuclear fragmentation whether for proton [6,7] or carbon therapy [8-10].

The potentiality of in-beam PET imaging can then be increased by the accurate knowledge of the cross sections of production of $\beta^{+}$emitters created during irradiation. Using the proper cross sections can lead to the direct measurement of the deposited dose distribution in the patient, or at least to a more accurate comparison of this distribution with the one obtained by the simulated treatment plan [11].

While cross section measurements of $\beta^{+}$emitters in the case of proton therapy can be found for instance in [12-17], a fairly small amount of literature data exists on the production cross sections of those induced by a carbon beam. To overcome this limitation, Helmbrecht et al. suggested in [18] to use measured $\beta^{+}$activity yields in a simulation code that can predict the $\beta^{+}$emitter distribution in a patient. However,

*Corresponding author: salvador@lpccaen.in2p3.fr to develop accurate models for the prediction of those distributions in generic Monte Carlo code like GEANT4 [19] or FLUKA [20], or to obtain a direct measurement of the delivered dose distribution, absolute production cross sections are mandatory.

In this way, we conducted an experiment in July 2016 at the GANIL facility (Grand Accélérateur National d'Ions Lourds, Caen, France) within the framework of France-Hadron. The goal was to obtain the production cross sections of several radioisotopes by nuclear interactions of a carbon beam on targets of medical interest (i.e., C, N, O). Different beam energies from $25 \mathrm{MeV} /$ nucleon to $95 \mathrm{MeV} /$ nucleon were used to extract data corresponding to the last centimeters of the carbon ion range in the patient.

Due to the data taking process (see Sec. II A), the cross sections of very short-lived $\beta^{+}$emitters such as ${ }^{9} \mathrm{C}\left(T_{1 / 2}=\right.$ $126.5 \mathrm{~ms})$ or even ${ }^{12} \mathrm{~N}\left(T_{1 / 2}=11.0 \mathrm{~ms}\right)$ cannot be extracted. Only radioisotopes with half-lives higher than a few seconds were considered, leaving us with the most abundant ones: ${ }^{10} \mathrm{C}$, ${ }^{11} \mathrm{C},{ }^{13} \mathrm{~N},{ }^{14} \mathrm{O}$, and ${ }^{15} \mathrm{O}$ (see Table I for the main properties of these $\beta^{+}$emitters). We also considered that the proportion of escaping radioisotopes due to momentum transfer with the beam particles was negligible for these peripheral collisions.

\section{EXPERIMENTAL SET-UP}

\section{A. General considerations}

The experimental set-up is partially shown in Fig. 1. The exit of the beam pipe was followed by PMMA degraders to adjust the beam energy from $95 \mathrm{MeV} /$ nucleon to $50 \mathrm{MeV} /$ nucleon and $25 \mathrm{MeV} /$ nucleon (Sec. II B). The DOSION ionization chamber [21] used as the beam monitor can then be seen (see Sec. II D for more details) as well as the $\gamma$ detection system along with the target propulsion arm. On the right side, the beam dump is also displayed. A plastic scintillator (not shown) placed in-beam at the beginning of the experiment and located midway between the target position and the beam-dump was used for calibration (Sec. II D). 
TABLE I. Positron emitter properties used in this work. Data extracted from [3].

\begin{tabular}{lccr}
\hline \hline Emitter & Half-life $(\mathrm{s})$ & Decay constant, $\lambda\left(\mathrm{s}^{-1}\right)$ & $E_{\max }(\mathrm{keV})$ \\
\hline${ }^{10} \mathrm{C}$ & $19.290(12)$ & $3.593(2) \times 10^{-2}$ & $1907.6(6)$ \\
${ }^{11} \mathrm{C}$ & $1221.8(8)$ & $5.673(4) \times 10^{-4}$ & $960.4(1)$ \\
${ }^{13} \mathrm{~N}$ & $597.90(24)$ & $1.159(1) \times 10^{-3}$ & $1198.5(3)$ \\
${ }^{14} \mathrm{O}$ & $70.606(18)$ & $9.817(2) \times 10^{-3}$ & $1808.2(1)$ \\
${ }^{15} \mathrm{O}$ & $122.24(16)$ & $5.670(7) \times 10^{-3}$ & $1732.0(5)$ \\
\hline \hline
\end{tabular}

The data taking process was carried out as follows: the targets were located in-beam during a short irradiation time of approximately $10 \mathrm{~s}$ and then pushed in a few hundreds of milliseconds to the $\gamma$ detection system for the detection of the $511 \mathrm{keV}$ annihilation $\gamma$ rays in coincidence for about an hour. The targets were also surrounded by two aluminum plates of $2 \mathrm{~mm}$ thick acting as converters for the escaping positrons in order to mostly keep them from annihilating away of the coincidence zone.

\section{B. Beam energies}

To obtain several beam energies, PMMA degraders of different thicknesses were inserted between the beam nozzle and the experimental set-up. The primary carbon beam energy from the GANIL facility was 94.98(9) $\mathrm{MeV} /$ nucleon. The energies of the beam after these degraders were calculated by numerical simulations taking into account the beam monitoring device. Table II gives the different beam energies obtained with the degraders as well as the percentage of charged particles created by nuclear interactions in the degraders and reaching the target. These percentages were evaluated by Monte Carlo simulations to be mostly protons and $\alpha$ particles (see [21] for further details).

\section{Targets}

In order to get the $\beta^{+}$emitter productions for a carbon therapy treatment, targets of medical interest were used.

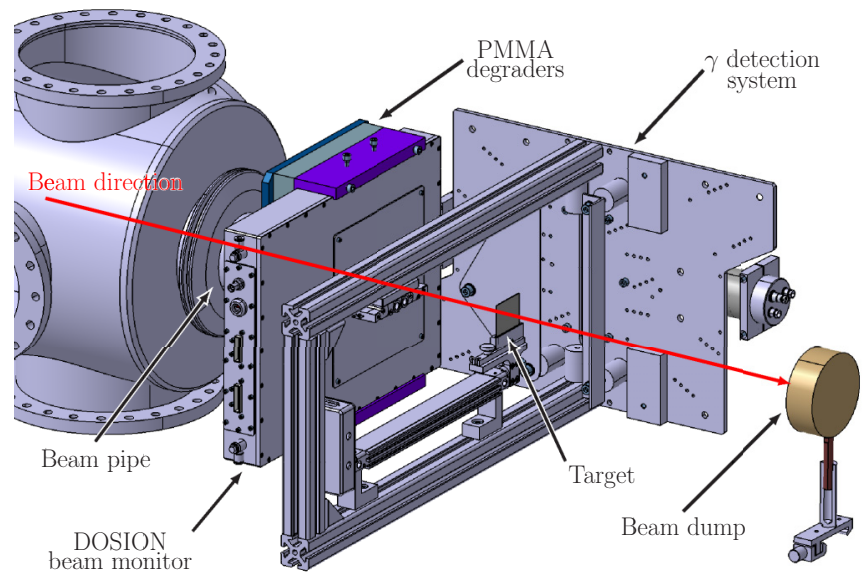

FIG. 1. Experimental set-up showing the different apparatus used for the measurement of the production cross sections of several $\beta^{+}$ emitters produced by a carbon beam on different targets.
TABLE II. Beam energies obtained with different thickness of energy degraders. Also mentioned, the percentage of beam fragments after the degrader.

\begin{tabular}{lcc}
\hline \hline $\begin{array}{l}\text { PMMA thickness } \\
(\mathrm{mm})\end{array}$ & $\begin{array}{c}\text { Beam energy } \\
(\mathrm{MeV} / \text { nucleon })\end{array}$ & $\begin{array}{c}\text { Fragments } \\
(\%)\end{array}$ \\
\hline 0 & 94.3 & 0 \\
13.9 & 47.8 & $5.5 \%$ \\
17.9 & 25.0 & $6.5 \%$ \\
\hline \hline
\end{tabular}

The ${ }^{12} \mathrm{C}$ beam particles were then interacting with carbon atoms in a graphite target (C). For comparative study of carbon isotopes, we used a polyethylene target $\left(\mathrm{CH}_{2}\right)$ at 94.3 $\mathrm{MeV} /$ nucleon and a second thicker graphite target at 47.8 $\mathrm{MeV} /$ nucleon. A boron nitride target (BN) was also used to obtain the emitter productions on nitrogen. Finally, a PMMA target $\left(\mathrm{C}_{5} \mathrm{H}_{8} \mathrm{O}_{2}\right)$ was irradiated to extract by reconstruction the cross sections on oxygen. Each target had a surface of approximately $5 \times 5 \mathrm{~cm}^{2}$.

Table III gives the different targets used for irradiation along with their thicknesses and area density values $\left(\rho_{A}\right)$. Due to the high area densities of the graphite and PMMA targets, only the data from the boron nitride target will be presented at 25.0 MeV/nucleon.

\section{Monitoring system}

The monitoring system had the crucial role of giving an accurate evaluation of the beam intensity during the target irradiation and to provide the two dimensional position and shape of the beam on the targets. In fact, due to the proximity of the detectors to the targets, the beam spatial informations had an impact on the evaluation of the detection efficiency of the system (see Sec. II F).

The system was composed of the DOSION ionization chamber located in-beam. It provides the two dimensional distribution of the beam and the charge deposited by the particles in real time using the FASTER [22] digital acquisition system developed in-house. A calibration procedure was conducted prior to the target irradiations by means of a retractable scintillating detector to measure the beam intensity.

TABLE III. Target properties used for irradiation and cross sections extraction for the three beam energies.

\begin{tabular}{lccc}
\hline \hline $\begin{array}{l}\text { Beam energy } \\
(\mathrm{MeV} / \text { nucleon })\end{array}$ & Target & $\begin{array}{c}\text { Thickness } \\
(\mathrm{mm})\end{array}$ & $\begin{array}{c}\rho_{A} \\
\left(\mathrm{mg} \mathrm{cm}^{-2}\right)\end{array}$ \\
\hline 94.3 & boron nitride & 2.0 & $390(6)$ \\
& graphite & 2.0 & $350(3)$ \\
& polyethylene & 4.0 & $355(1)$ \\
47.8 & PMMA & 4.0 & $462(9)$ \\
& boron nitride & 1.0 & $195(3)$ \\
& graphite & 1.0 & $175(2)$ \\
& graphite & 2.0 & $350(3)$ \\
25.0 & PMMA & 2.0 & $231(4)$ \\
\hline \hline & boron nitride & 0.5 & $97(1)$ \\
\hline
\end{tabular}




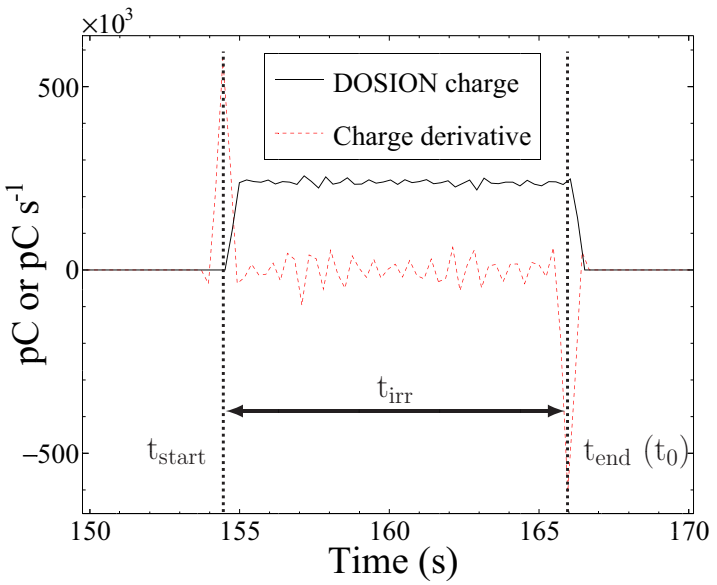

FIG. 2. Example of the collected charges in DOSION over time (solid black line) and the first derivative (dashed red line) to extract the start and end times $\left(t_{\text {start }}\right.$ and $\left.t_{\text {end }}\right)$ of the irradiation as well as the irradiation time, $t_{\text {irr }}$.

The beam intensity error was evaluated using the calibration coefficients to be approximately $3 \%$.

A more detailed description of DOSION and the calibration process can be found in a previous paper [21].

The number of ions impinging the targets were measured after extraction of the irradiation start $\left(t_{\text {start }}\right)$ and end times $\left(t_{\text {end }}\right)$ with a error of $2.4 \mathrm{~ms}$ by applying a numerical derivative on the plot of the collected charges versus time from DOSION (see Fig. 2 for an example). Given these times, the irradiation duration $t_{\text {irr }}$, the number of ions $N_{0}$ as well as the average position and sigma values (assuming a two-dimensional gaussian shape) of the beam were calculated. $t_{\text {end }}$ was then considered as the start $\left(t_{0}\right)$ of the $\gamma$ detection acquisition.

\section{E. Gamma detection system}

For the detection of the $\gamma$ rays emitted by the annihilation of the positrons in the target, two $\mathrm{CeBr}_{3}$ scintillation detectors were used. The entrance faces of the $38.5 \mathrm{~mm}$ in diameter and $38.5 \mathrm{~mm}$ thick scintillators were placed front-to-front at $4 \mathrm{~cm}$ from the center of the target (shown in Fig. 3).

The detection was made in coincidence mode in postprocessing to avoid the detection of annihilation $\gamma$ rays from radioisotopes produced in the environment (beam dump, air, etc.). The numerical acquisition used could sustain up to $10^{5}$

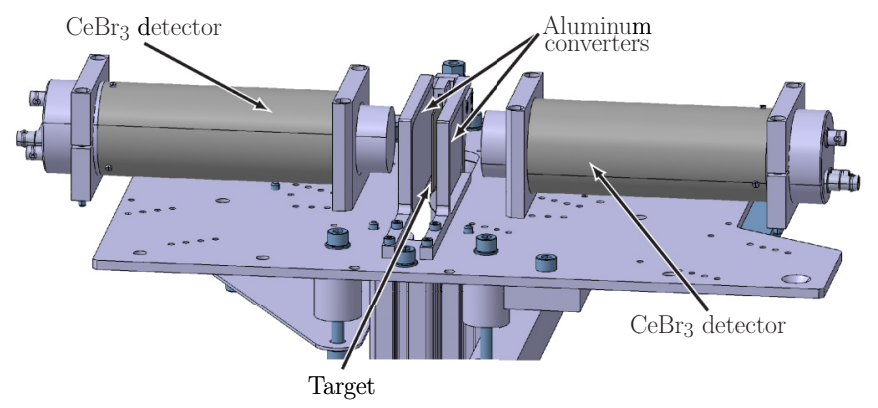

TABLE IV. Coincidence detection efficiencies for the 94.3 MeV/nucleon beam energy, evaluated by Monte Carlo simulations (last digit error in parentheses).

\begin{tabular}{lccccc}
\hline \hline \multirow{2}{*}{ Target } & \multicolumn{5}{c}{ Coincidence detector efficiency, $\epsilon_{\text {det }}(\%)$} \\
\cline { 2 - 6 } & ${ }^{10} \mathrm{C}$ & ${ }^{11} \mathrm{C}$ & ${ }^{13} \mathrm{~N}$ & ${ }^{14} \mathrm{O}$ & ${ }^{15} \mathrm{O}$ \\
\hline $\mathrm{BN}$ & $0.282(2)$ & $0.329(3)$ & $0.316(2)$ & $0.281(2)$ & - \\
$\mathrm{C}$ & $0.287(2)$ & $0.328(2)$ & - & - & - \\
$\mathrm{CH}_{2}$ & $0.282(2)$ & $0.326(2)$ & - & - & - \\
$\mathrm{PMMA}$ & $0.289(2)$ & $0.329(3)$ & $0.325(2)$ & $0.289(2)$ & $0.299(2)$ \\
\hline \hline
\end{tabular}

counts $\mathrm{s}^{-1}$ with no dead time considering the small count rate of each scintillation detector (approximately 6000 counts s ${ }^{-1}$ in singles at the end of the irradiation) and the fast decay time of the scintillators $(\sim 21 \mathrm{~ns})$.

\section{F. Detection efficiency evaluation}

The coincidence detection efficiencies of the system for the different isotopes and beam energies were calculated by Monte Carlo simulations using GEANT4.9.6.p02 [19]. The whole set-up was described in the simulations including the detectors and target holding materials that might had an effect on the $\gamma$ detection. The $\beta^{+}$emitter distributions were generated according to the DOSION beam shape and position for each target. The physics processes used in GEANT4 were only the electromagnetic and the radioactive decay processes to give the correct energy distribution of the positrons.

Each $511 \mathrm{keV} \gamma$-ray interaction with the scintillators was recorded and its deposited energy stored. The detection efficiency was then calculated as the number of coincidence events detected in the full energy peaks of the energy spectrum of both detectors, divided by the number of generated $\beta^{+}$ emitters (i.e., $10^{6}$ ). The coincidence detection efficiencies are rather low with values around $0.3 \%$. They mostly depend on the $\beta^{+}$kinetic energy due to escaping positrons from the coincidence zone. In fact, the smallest detection efficiencies are observed for isotopes with the highest positron end-point energies, i.e., ${ }^{10} \mathrm{C}$ and ${ }^{14} \mathrm{O}$. Moreover, the efficiencies depend on the beam energy by its shape and position on the targets. Table IV gives an example of the coincidence detection efficiencies, $\epsilon_{\text {det }}$, obtained for the $94.3 \mathrm{MeV} /$ nucleon beam energy and the different $\beta^{+}$emitters.

\section{ANALYSIS}

A decay time spectrum of the number of $511 \mathrm{keV} \gamma$ rays detected in coincidence was build for each acquisition by accumulating data with a variable time bin width. The bin width started from around $1 \mathrm{~s}$ up to $20 \mathrm{~s}$ at the end of the acquisition to account for radioisotopes with short and longer half-lives. The activity of the $\beta^{+}$emitters at the end of the beam irradiation $t_{0}$ were extracted by fitting the decay time spectrum with the sum of exponential decay functions:

$$
\sum_{i} A_{i} e^{-\lambda_{i} t}
$$

FIG. 3. Mechanical drawing of the $\gamma$ detection system. 
TABLE V. List of the $\beta^{+}$emitters produced in the different targets.

\begin{tabular}{lccccc}
\hline \hline Target & \multicolumn{5}{c}{ Positron emitter } \\
\cline { 2 - 5 } & ${ }^{10} \mathrm{C}$ & ${ }^{11} \mathrm{C}$ & ${ }^{13} \mathrm{~N}$ & ${ }^{14} \mathrm{O}$ & ${ }^{15} \mathrm{O}$ \\
\hline $\mathrm{BN}$ & $\checkmark$ & $\checkmark$ & $\checkmark$ & $\checkmark$ & \\
$\mathrm{C}$ & $\checkmark$ & $\checkmark$ & & & \\
$\mathrm{CH} \mathrm{H}_{2}$ & $\checkmark$ & $\checkmark$ & & & \\
PMMA & $\checkmark$ & $\checkmark$ & $\checkmark$ & $\checkmark$ & $\checkmark$ \\
\hline \hline
\end{tabular}

where $A_{i}$ is the activity and $\lambda_{i}$ the disintegration constant of the considered $i$ th isotope. The number of exponential decays included in the fit depended on the composition of the target (see Table $\mathrm{V}$ for the list of included isotopes).

Figure 4(a) shows the decay time spectrum of the graphite target with the exponential decays of ${ }^{10} \mathrm{C}$ and ${ }^{11} \mathrm{C}$. Figure 4(b) displays the time spectrum for the PMMA target with the exponential decays of ${ }^{10,11} \mathrm{C},{ }^{13} \mathrm{~N}$, and ${ }^{14,15} \mathrm{O}$ included.

After extraction of the initial $\beta^{+}$activity $A_{i}$ (in $\mathrm{Bq}$ ), the production cross sections ( $\sigma$ in $\mathrm{mb}$ ) were calculated according to Eq. (2), where $M_{\text {target }}$ is the considered target number of mass, $N_{0}$ is the number of measured beam particles during the irradiation time $t_{\text {irr }}$ (in s). $\mathcal{N}_{A}$ is the Avogadro number. The cross sections were corrected for the $\beta^{+}$emitter decays during
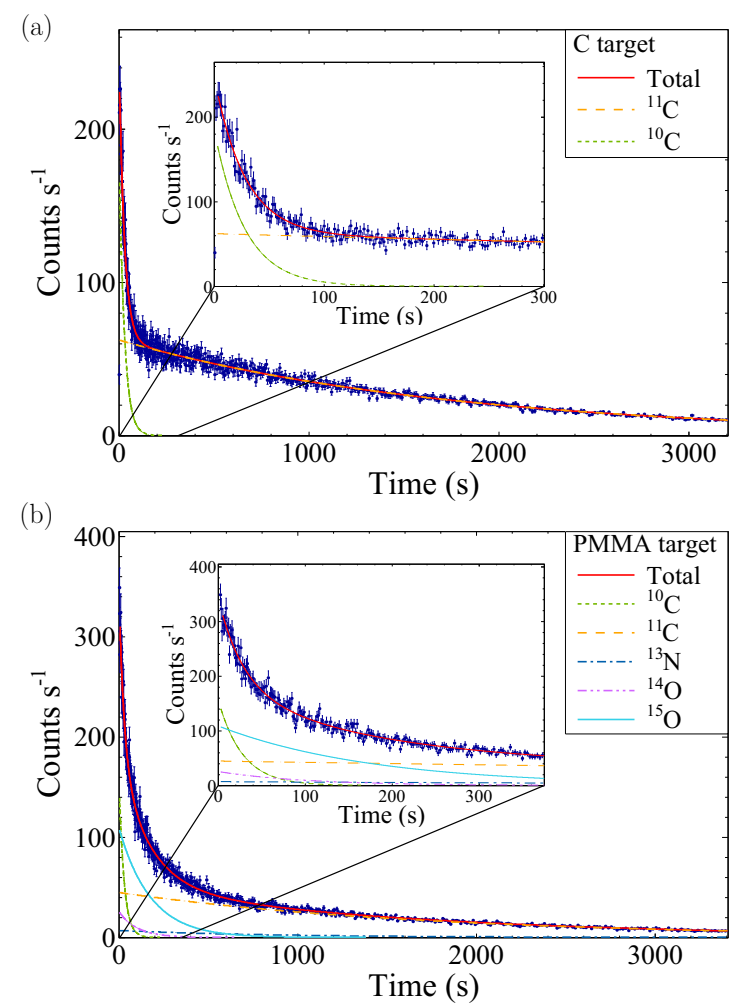

FIG. 4. Spectra of the number of $511 \mathrm{keV} \gamma$ rays detected in coincidence per second for (a) the graphite and (b) the PMMA target with a $94.3 \mathrm{MeV} /$ nucleon ${ }^{12} \mathrm{C}$ beam. The insets show close-up views on the short decay times. The total fit as well as the contributions of the individual nuclides included are shown.
TABLE VI. Averaged energies of the beam in the different targets for the different beam energies. The averaged energies for the two different graphite target thicknesses at $47.8 \mathrm{MeV} /$ nucleon are mentioned.

\begin{tabular}{lcccc}
\hline \hline \multirow{2}{*}{$\begin{array}{l}\text { Beam energy } \\
(\mathrm{MeV} / \text { nucleon})\end{array}$} & $\mathrm{BN}$ & $\mathrm{C}$ & $\mathrm{CH}_{2}$ & PMMA \\
\cline { 2 - 5 } Targets \\
\hline 94.3 & $91(4)$ & $90(5)$ & $90(5)$ & $89(5)$ \\
47.8 & $44(4)$ & $44(5) / 39(9)$ & - & $43(5)$ \\
25.0 & $22(3)$ & - & - & - \\
\hline \hline
\end{tabular}

the irradiation of the target $\left(\frac{t_{\mathrm{irr}}}{1-e^{-\lambda_{i} \cdot t_{\mathrm{irr}}}}\right)$.

$$
\sigma_{i}=\frac{A_{i} M_{\mathrm{target}} t_{\mathrm{irr}}}{N_{0} \epsilon_{\mathrm{det}} \rho_{A}\left(1-e^{-\lambda_{i} \cdot t_{\mathrm{irr}}}\right) \mathcal{N}_{A}} \times 10^{27} .
$$

The error bars $\left(\varepsilon_{\sigma_{i}}\right)$ were calculated using all the contributions of the different systematic and statistical errors, considering the good approximation that none were correlated [cf. Eq. (3)]:

$$
\begin{aligned}
\varepsilon_{\sigma_{i}} & =\sigma_{i} \sqrt{\sum_{j}\left(\frac{\varepsilon_{j}}{j}\right)^{2}}, \\
\text { with } \quad j & =\left\{A_{i}, t_{\mathrm{irr}}, N_{0}, \epsilon_{\mathrm{det}}, \rho_{A}\right\} .
\end{aligned}
$$

\section{RESULTS}

In this work, we considered that the target thicknesses were small enough to have a constant interaction cross section with the beam. However, we evaluated the beam energies after the targets by Monte Carlo simulations in order to give an average energy value at which the cross sections were extracted. Table VI summarizes those averaged energies. The cross sections given in the following figures will then be displayed at these averaged energies, where the error bars represent the energy window of the beam.

Moreover, considering the approximate total interaction cross section of ${ }^{12} \mathrm{C}$ on carbon of about 1 barn (cf. [23]), we neglected the probability to have two following interactions per beam particle (around $10^{-4}$ ) for all the targets.

\section{A. Elemental targets}

The graphite and polyethylene targets used in this work were considered to be elemental targets of carbon (C) and reconstructed carbon $\left(\mathrm{C}_{\mathrm{rec}}\right)$, respectively. However, concerning the boron nitride target $(\mathrm{N})$, nuclear interactions on the two isotopes of boron also lead to the production of carbon isotopes. In the following data and figures, production cross sections for these isotopes are noted to have the contributions of both boron and nitrogen.

Figure 5(a) presents the measured production cross sections of the $\beta^{+}$emitters on carbon at 94.3 and $47.8 \mathrm{MeV} /$ nucleon.

In the $C$ target, the differences in cross sections at 94.3 $\mathrm{MeV} /$ nucleon extracted from graphite and polyethylene are comparable with a difference of approximately $10 \%$, within $2 \sigma$. At $47.8 \mathrm{MeV} /$ nucleon, the difference between the two graphite targets (below $15 \%$ for both isotopes) can easily be 

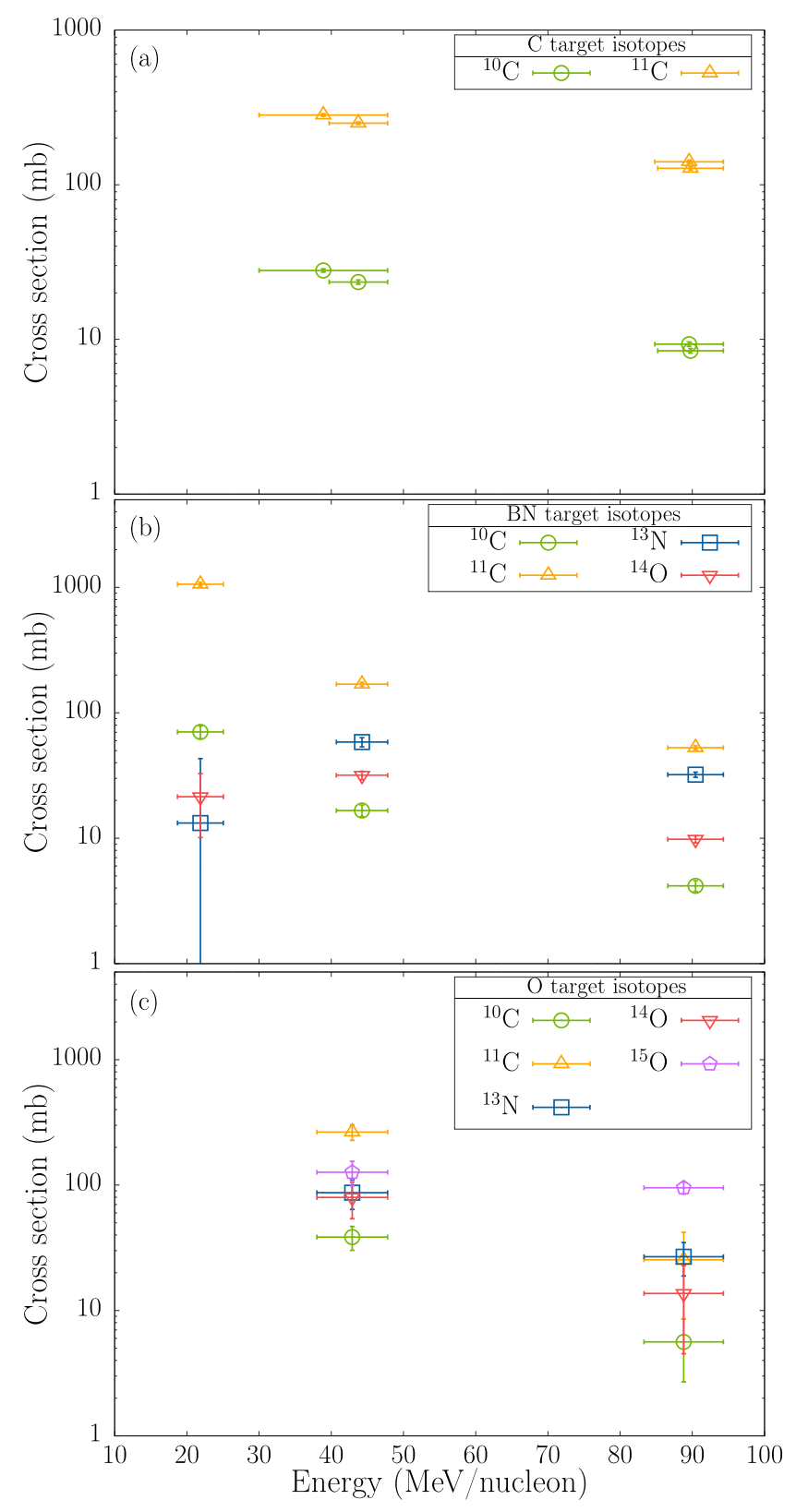

FIG. 5. Production cross sections of $\beta^{+}$emitters extracted for (a) the carbon, (b) the boron nitride targets as well as (c) the reconstructed oxygen target at three beam energies. The given error bars on the energy represent the entrance and exit energy of the beam. For the boron nitride target, the ${ }^{10} \mathrm{C}$ and ${ }^{11} \mathrm{C}$ have the contributions of both boron and nitrogen target nuclei.

explained by the higher area density of the $2 \mathrm{~mm}$ thick one leading to a lower average energy. Due to the stripping of one more neutron by the beam particles, the cross section of ${ }^{10} \mathrm{C}$ is approximately $10 \times$ smaller than that of ${ }^{11} \mathrm{C}$.

For boron nitride in Fig. 5(b), the production cross section of ${ }^{11} \mathrm{C}$ is higher than ${ }^{13} \mathrm{~N}$. This can only be explained by the production of ${ }^{11} \mathrm{C}$ on ${ }^{11} \mathrm{~B}$ by the exchange of a proton to a neutron from the beam ion. Due to the same exchange mechanism, this interaction cross section should be of the same order of magnitude that producing ${ }^{14} \mathrm{O}$ on ${ }^{14} \mathrm{~N}$ nuclei
TABLE VII. Extracted cross sections in $\mathrm{mb}$ of the different $\beta^{+}$emitters produced in the targets with a ${ }^{12} \mathrm{C}$ beam at 94.3 $\mathrm{MeV} /$ nucleon. Uncertainties in parentheses.

\begin{tabular}{lcccccc}
\hline \hline Target & $\begin{array}{c}\text { Energy } \\
(\mathrm{MeV} / \text { nucleon })\end{array}$ & ${ }^{10} \mathrm{C}$ & ${ }^{11} \mathrm{C}$ & ${ }^{13} \mathrm{~N}$ & ${ }^{14} \mathrm{O}$ & ${ }^{15} \mathrm{O}$ \\
\cline { 3 - 7 } & $90(4)$ & $4(1)^{\mathrm{a}}$ & $53(2)^{\mathrm{a}}$ & $32(2)$ & $10(1)$ & - \\
$\mathrm{N}$ & $90(5)$ & $8(1)$ & $128(3)$ & - & - & - \\
$\mathrm{C}$ & $90(5)$ & $9(1)$ & $141(4)$ & - & - & - \\
$\mathrm{C}_{\text {rec }}$ & $89(5)$ & $6(3)$ & $25(17)$ & $27(8)$ & $14(9)$ & $95(11)$ \\
$\mathrm{O}_{\text {rec }}$ & $89(5)$ & $53(4)$ & $689(24)$ & $54(11)$ & $27(13)$ & $190(15)$ \\
PMMA & & & & & &
\end{tabular}

${ }^{\mathrm{a}}$ Contributions of both boron and nitrogen nuclei.

(around $10 \mathrm{mb}$ at $94.3 \mathrm{MeV} /$ nucleon). As natural boron is also composed of approximately $20 \%$ of ${ }^{10} \mathrm{~B}$, the production cross sections of ${ }^{10} \mathrm{C}$ undergo the same process. Concerning ${ }^{14} \mathrm{O}$ and ${ }^{13} \mathrm{~N}$, we think that they are mostly produced from ${ }^{14} \mathrm{~N}$ nuclei, the first through the charge exchange mechanism and the second by neutron stripping.

In order to retrieve the production cross section on oxygen, we used the same reconstruction method as found in [24] on the PMMA target using the $\mathrm{C}$ cross sections. In fact, due to the good confidence of the carbon target cross sections, they can be subtracted to those on PMMA composed of $\mathrm{C}_{5} \mathrm{H}_{8} \mathrm{O}_{2}$ to obtain the production cross sections on oxygen using the following formula:

$$
\sigma_{\mathrm{O}}=\frac{\sigma_{\mathrm{PMMA}}-5 \sigma_{\mathrm{C}}}{2} .
$$

Figure 5(c) shows the reconstructed production cross sections of the $\beta^{+}$emitters on oxygen at 94.3 and $47.8 \mathrm{MeV} /$ nucleon. The cross section of ${ }^{15} \mathrm{O}$ naturally dominates at the highest energy. The production of ${ }^{14} \mathrm{O}$ is however smaller than those of ${ }^{13} \mathrm{~N}$ and ${ }^{11} \mathrm{C}$, which are both comparable with a cross section of $\sim 25 \mathrm{mb}$. However at $47.8 \mathrm{MeV} /$ nucleon, ${ }^{11} \mathrm{C}$ has the highest production cross section above ${ }^{15} \mathrm{O}$.

For all the targets and isotopes the production cross sections naturally increase when the beam energy decreases. The production cross sections of the $\beta^{+}$emitters studied in this work are finally summarized in Tables VII to IX.

\section{B. Comparison with existing data}

Existing data in the literature are very scarce. In fact, the only experimental cross sections found on the interaction

TABLE VIII. Extracted cross sections in mb of the different $\beta^{+}$emitters produced in the targets with a ${ }^{12} \mathrm{C}$ beam at 47.8 $\mathrm{MeV} /$ nucleon. Uncertainties in parentheses.

\begin{tabular}{lcccccc}
\hline \hline Target & \multirow{2}{*}{$\begin{array}{c}\text { Energy } \\
(\mathrm{MeV} / \text { nucleon })\end{array}$} & ${ }^{10} \mathrm{C}$ & ${ }^{11} \mathrm{C}$ & ${ }^{13} \mathrm{~N}$ & ${ }^{14} \mathrm{O}$ & ${ }^{15} \mathrm{O}$ \\
\cline { 3 - 7 } & $44(4)$ & $17(2)^{\mathrm{a}}$ & $169(6)^{\mathrm{a}}$ & $58(5)$ & $32(2)$ & - \\
$\mathrm{N}$ & $44(4)$ & $24(1)$ & $250(5)$ & - & - & - \\
$\mathrm{C}_{1 m m}$ & $39(9)$ & $28(1)$ & $282(5)$ & - & - & - \\
$\mathrm{C}_{2 m m}$ & $43(5)$ & $39(8)$ & $265(38)$ & $87(23)$ & $80(26)$ & $127(28)$ \\
$\mathrm{O}_{\text {rec }}$ & $43(5)$ & $194(12)$ & $1781(53)$ & $174(33)$ & $160(37)$ & $253(40)$ \\
PMMA & & & & & &
\end{tabular}

${ }^{\mathrm{a}}$ Contributions of both boron and nitrogen nuclei. 
TABLE IX. Extracted cross sections in $\mathrm{mb}$ of the different $\beta^{+}$emitters produced in the targets with a ${ }^{12} \mathrm{C}$ beam at 25.0 $\mathrm{MeV} /$ nucleon. Uncertainties in parentheses.

\begin{tabular}{lccccc}
\hline \hline Target & \multirow{2}{*}{$\begin{array}{c}\text { Energy } \\
\text { (MeV/nucleon) }\end{array}$} & ${ }^{10} \mathrm{C}$ & ${ }^{11} \mathrm{C}$ & ${ }^{13} \mathrm{~N}$ & ${ }^{14} \mathrm{O}$ \\
\hline $\mathrm{N}$ & $22(3)$ & $70(8)^{\mathrm{a}}$ & $1059(39)^{\mathrm{a}}$ & $13(30)$ & $21(11)$ \\
\hline \hline
\end{tabular}

${ }^{\mathrm{a}}$ Contributions of both boron and nitrogen nuclei.

of a ${ }^{12} \mathrm{C}$ beam on a carbon target with related energies are given in [25]. They reported on the production of ${ }^{11} \mathrm{C}$ at $100 \mathrm{MeV} /$ nucleon with a cross section of $88 \pm 3 \mathrm{mb}$ compared to $128 \pm 3 \mathrm{mb}$ in this work. Fiedler et al. [26], extracted the number of ${ }^{10,11} \mathrm{C},{ }^{13} \mathrm{~N}$, and ${ }^{15} \mathrm{O}$ per $10^{6}$ incident ${ }^{12} \mathrm{C}$ ions of $337.5 \mathrm{MeV} /$ nucleon on graphite and water. Following their equation on the extraction of the cross section on thick targets, we estimated the production cross sections integrated over the entire ion range. The cross sections of ${ }^{10} \mathrm{C}(16 \pm 3 \mathrm{mb}),{ }^{11} \mathrm{C}$ $(211 \pm 32 \mathrm{mb}),{ }^{13} \mathrm{~N}(36 \pm 5 \mathrm{mb})$, and ${ }^{15} \mathrm{O}(217 \pm 32 \mathrm{mb})$ are higher by a factor of 2 compared to the present work. In Monte Carlo simulations, Pshenichnov et al. [27], reported a GEANT4 ${ }^{11} \mathrm{C}$ cross section on graphite with $100 \mathrm{MeV} /$ nucleon ${ }^{12} \mathrm{C}$ ions of $144 \pm 14 \mathrm{mb}$. Table X summarizes those data with the one obtained in this work.

Overall, the data measured in this work are of the same order of magnitude compared to the literature. It is worth notice that our ${ }^{11} \mathrm{C}$ cross section compared to Yashima et al. is higher by 44\% while it is smaller than the Monte Carlo simulations of Pshenichnov et al. by $12 \%$.

\section{CONCLUSION}

In this paper, we report on the measurements of the cross sections of production of $\beta^{+}$emitters related to carbon therapy.
TABLE X. Comparison with several cross sections obtained from reactions of ${ }^{12} \mathrm{C}$ beams found in the literature.

\begin{tabular}{lcccc}
\hline \hline Isotope & Fiedler $^{\mathrm{a}}$ & Yashima $^{\mathrm{b}}$ & Pshenichnov $^{\mathrm{c}}$ & This work $^{\mathrm{d}}$ \\
\hline${ }^{10} \mathrm{C}$ & $16(2)$ & - & - & $8(1)$ \\
${ }^{11} \mathrm{C}$ & $211(32)$ & $88(3)$ & $144(14)$ & $128(3)$ \\
${ }^{13} \mathrm{~N}$ & $36(5)$ & - & - & $27(8)$ \\
${ }^{15} \mathrm{O}$ & $217(32)$ & - & - & $95(11)$ \\
\hline \hline
\end{tabular}

${ }^{\mathrm{a}}$ Cross sections estimated from [26] and a ${ }^{12} \mathrm{C}$ beam energy of $337.5 \mathrm{MeV} /$ nucleon in graphite and water integrated over the ion range.

${ }^{\mathrm{b}}$ From [25], $100 \mathrm{MeV} /$ nucleon in graphite.

${ }^{\mathrm{c}}$ GEANT4 calculations from [27] at $100 \mathrm{MeV} /$ nucleon in graphite.

${ }^{\mathrm{d}} 95 \mathrm{MeV} /$ nucleon in graphite and reconstructed oxygen.

The ${ }^{10,11} \mathrm{C},{ }^{13} \mathrm{~N}$, and ${ }^{14,15} \mathrm{O}$ cross sections were extracted for the interaction of a ${ }^{12} \mathrm{C}$ beam with targets of medical interest such as carbon, nitrogen, and oxygen. Concerning the nitrogen target, it was chosen for its higher proportion in soft tissues of the human body than the commonly used calcium target. It showed that the contribution of ${ }^{13} \mathrm{~N}$ in the signal of PET images of the dose distribution in a carbon ion treatment is not negligible, especially considering its longer half-life (597.9 s) compared to oxygen isotopes.

From the detection point-of-view, it is clear that the cross sections accuracy are mainly influenced by the low detector coincidence efficiencies. Their evaluation by Monte Carlo simulations taking into account the complete experimental set-up and the beam shape was the best solution to limit the measurement errors.

To validate the reconstruction process of the oxygen target, additional data will be extracted on a solid water target in future measurements. Further experiments will also be conducted in other carbon beam facilities up to $400 \mathrm{MeV}$ /nucleon beam energies in order to cover the entire range of carbon ions in matter.
[1] D. Schardt, T. Elsässer, and D. Schulz-Ertner, Rev. Mod. Phys. 82, 383 (2010).

[2] A. Mairani, T. T. Böhlen, I. Dokic, G. Cabal, S. Brons, and T. Haberer, Int. J. Rad. Biol. 89, 782 (2013).

[3] http://www.nndc.bnl.gov/nudat2/.

[4] K. Gunzert-Marx, H. Iwase, D. Schardt, and R. S. Simon, New J. Phys. 10, 075003 (2008).

[5] Y. Kusano, T. Kanai, Y. Kase et al., Med. Phys. 34, 193 (2007).

[6] A. Miyatake, T. Nishio, T. Ogino, N. Saijo, H. Esumi, and M. Uesaka, Med. Phys. 37, 4445 (2010).

[7] K. Parodi, H. Paganetti, H. A. Shih et al., Int. J. Rad. Oncol. Biol. Phys. 68, 920 (2007).

[8] D. Schulz-Ertner, A. Nikoghosyan, C. Thilmann et al., Int. J. Rad. Oncol. Biol. Phys. 58, 631 (2003).

[9] W. Enghardt, P. Crespo, F. Fiedler, R. Hinz, K. Parodi, J. Pawelke, and F. Pönisch, Nucl. Instrum. Methods Phys. Res. A 525, 284 (2004).

[10] F. Fiedler, G. Shakirin, J. Skowron et al., Phys. Med. Biol. 55, 1989 (2010).
[11] K. Parodi, A. Mairani, S. Brons et al., Phys. Med. Biol. 57, 3759 (2012)

[12] K. Kettern, Y. Shubin, G. Steyn, T. van der Walt, H. Coenen, and S. Qaim, Appl. Rad. Isot. 60, 939 (2004).

[13] S. W. Kitwanga, P. Leleux, P. Lipnik, and J. Vanhorenbeeck, Phys. Rev. C 40, 35 (1989).

[14] J. M. Sisterson, A. M. Koehler, and R. F. Eilbert, Phys. Rev. C 18, 582 (1978).

[15] A. S. Iljinov, V. G. Semenov, M. P. Semenova, N. M. Sobolevsky, and L. V. Udovenko, Production of Radionuclides at Intermediate Energies (Springer-Verlag, Berlin, 1991).

[16] Online library on experimental nuclear reaction data http://www.nndc.bnl.gov/exfor/exfor.htm.

[17] Charged-particle cross section database for medical radioisotope production https://www-nds.iaea.org/medical/.

[18] S. Helmbrecht, M. Priegnitz, W. Enghardt, H. Rohling, and F. Fiedler, IEEE Trans. Nucl. Sci. 63, 61 (2016).

[19] S. Agostinelli et al., Nucl. Instrum. Methods Phys. Res. A 506, 250 (2003).

[20] G. Battistoni et al., Front. Oncol. 6, 116 (2016). 
[21] G. Boissonnat, J.-M. Fontbonne, J. Colin et al., Nucl. Instrum. Methods Phys. Res. A 856, 1 (2017).

[22] http://faster.in2p3.fr.

[23] L. Sihver, M. Lantz, M. Takechi, A. Kohama, A. Ferrari, F. Cerutti, and T. Sato, Adv. Space Res. 49, 812 (2012).

[24] J. Dudouet, D. Juliani, J.-C. Angélique et al., Phys. Rev. C 88, 024606 (2013).
[25] H. Yashima, Y. Uwamino, H. Iwase, H. Sugita, T. Nakamura, S. Ito, and A. Fukumura, Radiochim. Acta 91, 689 (2003).

[26] F. Fiedler, P. Crespo, K. Parodi, M. Sellesk, and W. Enghardt, IEEE Trans. Nucl. Sci. 53, 2252 (2006).

[27] I. Pshenichnov, A. Larionov, I. Mishustin, and W. Greiner, Phys. Med. Biol. 52, 7295 (2007). 